\title{
Emergency cases following elective colonoscopy: latrogenic colonic perforation
}

Ebubekir Gündeș, Hüseyin Çiyiltepe, Ulaș Aday, Durmuș Ali Çetin, Aziz Serkan Senger, Orhan Uzun, Kamuran Cumhur Değer, Mustafa Duman, Erdal Polat

ABSTRACT Objective: Our aim in this study was to present the cases of our patients who contracted colonic perforation during elective colonoscopy and became emergency cases; we also discuss treatment modalities along with literature reports on the subject.

Material and Methods: Cases of patients who contracted iatrogenic colonic perforation following endoscopy of the colorectal system between January 2009 and December 2015 at Kartal Koșuyolu Yüksek ihtisas Training and Research Hospital's Endoscopy Unit were reviewed retrospectively.

Results: Within the duration of the study, 5.586 patients underwent colonoscopies at our hospital; $7(0.12 \%)$ of these patients contracted iatrogenic colonic perforation. Three (42.8\%) of these patients were male, four (57.2\%) were female, and their mean age was 69 years (46 to 84). Six (85.7\%) patients were diagnosed intraoperationally, while one $(14.3 \%)$ patient was diagnosed 12 hours after the procedure. The perforation area was the sigmoid colon in six patients and the ascending colon in one patient; all patients underwent surgery. Four patients were discharged with no complications. One of the remaining three patients had enterocutaneous fistula, one had acute renal failure, and one died of sepsis.

Conclusion: The progress of perforation due to colonoscopy varies according to the underlying diseases, the mechanism of perforation formation, the treatment modality used, and the experience of the physicians treating the patient. Special attention should be paid to senior and comorbid patients receiving therapeutic procedures during colonoscopy.

Keywords: Colon, colonoscopic perforation, endoscopy

Cite this paper as: Gündeş E, Çiyiltepe H, Aday U, Çetin DA, Senger AS, Uzun 0 , et al. Emergency cases following elective colonoscopy: latrogenic colonic perforation. Turk J Surg 2017; 33: 248-252.

Department of Gastroenterology Surgery, Kartal Koşuyolu Yüksek İhtisas Training and Research Hospital, İstanbul, Turkey

This study was presented at the IV. National Gastroenterology Surgery Congress, 27 April-1 May, 2016, Antalya, Turkey.

Address for Correspondence Ebubekir Gündes e-mail:ebubekir82@hotmail.com

Received: 02.04.2016 Accepted: 26.07.2016

\section{OCopyright 2017} by Turkish Surgical Association

\section{INTRODUCTION}

Colonoscopy is commonly used in the diagnosis, treatment, and follow-up of colorectal diseases. It is generally acknowledged to be a safe procedure. The most frequent colonoscopy-related complication is post-polypectomy bleeding. The number of patients necessitating surgical intervention related to bleeding is very low (1). Colonoscopy-related colonic perforation is seen less than bleeding; however, it is still a significant complication that can lead to morbidity and mortality (2). The prevalence of post-colonoscopic perforation is $0.03 \%$ to $0.8 \%$ in diagnostic colonoscopy procedures, while it varies between $0.3 \%$ and $3 \%$ in therapeutic colonoscopies (3). There is still no consensus on the optimal treatment of iatrogenic colonic perforations because there are no prospective randomized and controlled studies in the literature. In this study, we present the cases of our patients who contracted colonic perforation during elective colonoscopy and who were transformed into emergency cases, along with their treatment modalities.

\section{MATERIAL AND METHOD}

\section{The Patients}

The cases of patients who contracted iatrogenic colonic perforation following endoscopy of the colorectal system between January 2009 and December 2015 at Kartal Koşuyolu Yüksek İhtisas Training and Research Hospital's Endoscopy Unit were reviewed retrospectively. The study was made according to Helsinki Declaration.

The total numbers of diagnostic and interventional colonoscopy and sigmoidoscopy procedures along with the total number of polypectomy and biopsy procedures conducted within the scope of interventional colonoscopy were determined within the designated timeframe of the study.

Endoscopic investigations are performed by gastroenterology surgery specialists and sub-specialty residents with gastroenterology specialists at the endoscopy unit of our hospital. All the patients signed detailed informed consent forms before the procedure. Patients who recently experienced myocardial 
Table 1. Clinical and demographic characteristics of the patients

\begin{tabular}{|lllllllll|} 
& Age & Sex & Comorbidities & ASA & Procedure & Indication for procedure & Diverticulosis \\
\hline 1 & 71 & K & HT, DM & 2 & Colonoscopy & Anemia & Yes \\
\hline 2 & 70 & K & MVR, HT, DM & 3 & Colonoscopy & Anemia & Yes \\
\hline 3 & 46 & K & & 1 & Colonoscopy & Hematochezia & No - polipectomy \\
\hline 4 & 74 & K & HT, DM, AF & 3 & Colonoscopy & Constipation & Yes \\
\hline 5 & 65 & E & & 1 & Colonoscopy & Change in bowel habits & Yes & No \\
\hline 6 & 84 & E & COPD, DM, HT & 3 & Colonoscopy & Anemia & Yes \\
\hline 7 & 68 & E & CABG, HT & 3 & Colonoscopy & Change in bowel habits & \\
\hline
\end{tabular}

HT: hypertension; DM: diabetes mellitus; MVR: mitral valve replacement; AF: atrial fibrillation; CABG: coronary artery bypass graft; COPD: chronic obstructive pulmonary disease

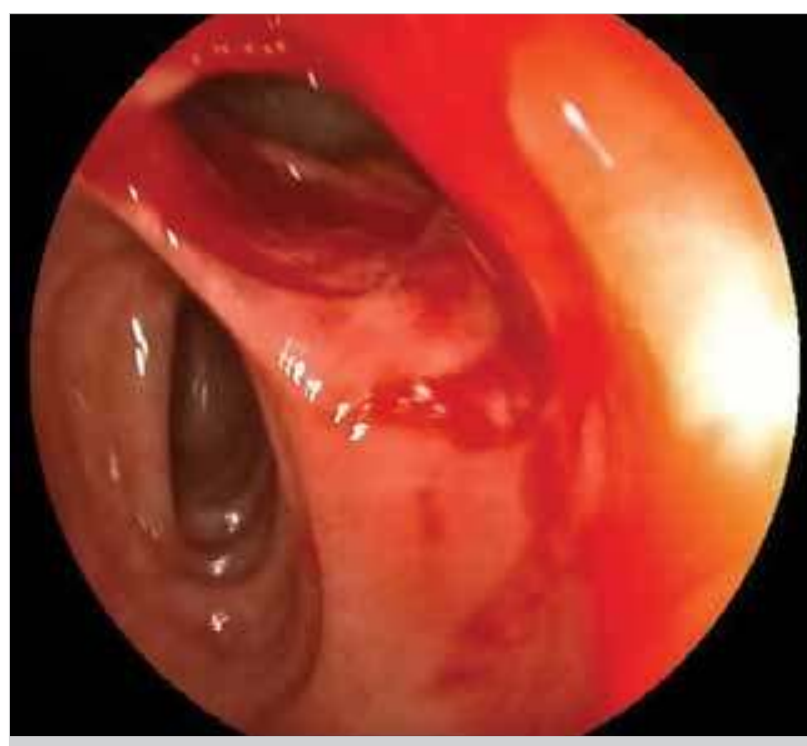

Figure 1. The perforated site was the sigmoid colon

infarction, had poor performance statuses, were diagnosed with serious arrhythmia, had acute phase diverticulitis, and who had coagulation disorders requiring biopsy or polypectomy did not receive the procedure.

The detailed clinical and demographic characteristics and colonoscopy reports of the patients diagnosed with perforation were investigated. The age, sex, additional disease, previous history of abdominal surgery, colonoscopy indication, American Society of Anesthesiologists (ASA) scoring, perforation area, presence of diverticulum, polypectomy, diagnosis and treatment method of the perforation, period of surgery for patients who underwent surgery, surgical technique, duration of hospitalization, and postoperative complications of the patients were reviewed.

\section{The Procedure}

Standard colon preparation was conducted using $500 \mathrm{mg}$ Sennoside (XM solution, Yenişehir Lab, İstanbul, Turkey) and $118 \mathrm{ml}$ sodium dihydrogen/disodium phosphate enema (B.T. Enema, Yenişehir Lab, İstanbul, Turkey). Propofol (1\%, Fresenius Kabi, İstanbul, Turkey) and fentanyl citrate $(0.5 \mathrm{mg} / 10$ $\mathrm{mL}$, VEM, İstanbul, Turkey) were used for premedication. A Fujinon 530 WL4 590 WL4 (Fujınon, Willich, Germany) Olympus 160 VR video-colonoscopy tool, polypectomy noose, and coagulation catheters (Olympus, Japan) were utilized during the procedure.

\section{Statistical Analysis}

Statistical Package for the Social Sciences version 21.0 (IBM Corp.; Armonk, NY, USA) computer software was used for the bio-statistical analyses.

\section{RESULTS}

Within the duration of the study, 5,586 patients underwent colonoscopies at our hospital; $7(0.12 \%)$ of these patients contracted iatrogenic colonic perforation. Three (42.8\%) of these patients were male, four (57.2\%) were female, and their mean age was 69 years (46-84). Colonoscopic indications of the patients with perforations included investigation of the etiology of anemia in three (42.8\%) patients, constipation and changes in intestinal habits in three (42.8\%) patients, and rectal bleeding in one (14.3\%) patient. None of the patients had a history of previous abdominal surgery. Six $(85.7 \%)$ of these patients underwent diagnostic colonoscopy, while one underwent therapeutic colonoscopy. Polypectomy was performed as the therapeutic procedure. The clinical and demographic data of the patients are summarized in Table 1.

While six (85.7\%) patients were diagnosed during the procedure (Figure 1), one (14.3\%) was diagnosed 12 hours after the procedure was completed. The case of the patient who was diagnosed 12 hours after the procedure was evaluated to be delayed diagnosis. The $\mathrm{X}$-ray results for the patients observed to have perforation areas during the procedure showed pneumoperitonium (Figure 2). In the delayed case, however, computerized tomography was used to diagnose the patient. The perforation area was the sigmoid colon in six patients and the ascending colon in one patient. Five of the patients with sigmoid colon perforations had diverticulum perforations. The patient with the ascending colon perforation had a polypectomy-related perforation.

All the patients diagnosed with colonoscopy-related iatrogenic colonic perforation received laparotomies: primary repair was performed in six patients, while the Hartmann procedure was performed in the delayed diagnosis patient. Four patients (57.2\%) were discharged with no postoperative complications. The patient with perforation in the ascending colon had leakage following primary repair. The patient was re-operated, and a right hemicolectomy and ile- 
Table 2. Diagnosis and treatment

\begin{tabular}{|c|c|c|c|c|c|c|c|}
\hline & $\begin{array}{l}\text { Time of } \\
\text { diagnosis }\end{array}$ & $\begin{array}{l}\text { Perforation } \\
\text { area }\end{array}$ & $\begin{array}{l}\text { Time between } \\
\text { colonoscopy } \\
\text { and operation }\end{array}$ & $\begin{array}{l}\text { Surgical } \\
\text { intervention }\end{array}$ & Complications & $\begin{array}{l}\text { Length of stay } \\
\text { in hospital }\end{array}$ & $\begin{array}{l}\text { Results and } \\
\text { follow-up }\end{array}$ \\
\hline 1 & During colonoscopy & Sigmoid & $<12 \mathrm{~h}$ & Primary suture repair & & 7 & Discharged \\
\hline 2 & During colonoscopy & Sigmoid & $<12 \mathrm{~h}$ & Primary suture repair & ARF & 18 & Discharged \\
\hline 3 & During colonoscopy & $\begin{array}{l}\text { Ascending } \\
\text { colon }\end{array}$ & $<12 \mathrm{~h}$ & Primary suture repair & $\begin{array}{l}\text { Leak } \\
\text { (reoperation) }\end{array}$ & 20 & $\begin{array}{l}\text { Discharged-stoma } \\
\text { closure in } 6 \text { months }\end{array}$ \\
\hline 4 & $\begin{array}{l}\text { Follow-up after } \\
\text { colonoscopy }\end{array}$ & Sigmoid & $>12 \mathrm{~h}$ & Hartman's colostomy & & 7 & $\begin{array}{l}\text { Discharged-stoma } \\
\text { closure in } 6 \text { months }\end{array}$ \\
\hline 5 & During colonoscopy & Sigmoid & $<12 \mathrm{~h}$ & Primary suture repair & & 7 & Discharged \\
\hline 6 & During colonoscopy & Sigmoid & $<12 \mathrm{~h}$ & Primary suture repair & & 8 & Discharged \\
\hline 7 & During colonoscopy & Sigmoid & $<12 \mathrm{~h}$ & Primary suture repair & $\begin{array}{l}\text { Acute COPD } \\
\text { exacerbation, } \\
\text { pneumonia, } \\
\text { sepsis }\end{array}$ & 8 & Exitus \\
\hline
\end{tabular}

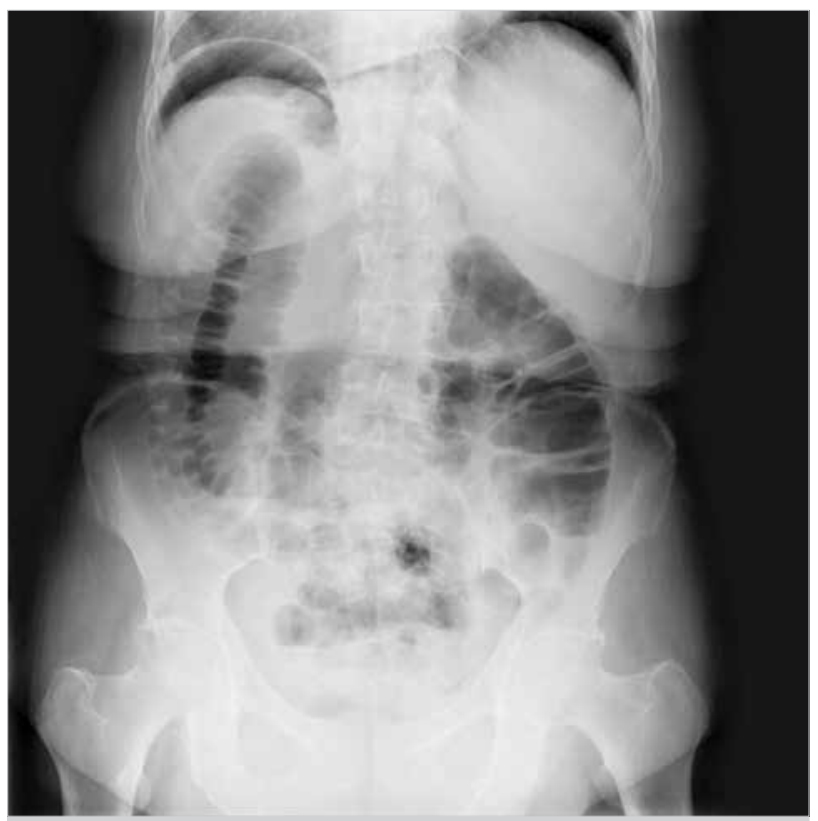

Figure 2. X-ray demonstrating bilateral subdiaphragmatic free air

ostomy were performed. This patient's ileostomy was closed about six months after the procedure without any problems. One patient contracted acute renal failure and required dialysis. The patient's renal functions improved during followup, and the patient did not require dialysis after discharge. One patient, however, died on the postoperative $8^{\text {th }}$ day because of serious comorbidity and complications. The mean duration of hospitalization for the cases was 10.7 (7 to 20) days. The diagnoses, treatments, and follow-up results of the patients are summarized in Table 2.

\section{DISCUSSION}

Colonoscopy is commonly used as a diagnostic and therapeutic tool in colorectal diseases. The number of patients receiving this procedure is increasing; consequently, the number of complications related to this procedure has increased. Perforations seen during colonoscopy are rare; however, they are serious complications that generally necessitate surgical inter- vention with a high morbidity-mortality rate $(2,3)$. Although their frequencies vary according to the center where they are performed, complications are seen at a rate of $0.03 \%$ to $0.8 \%$ in diagnostic colonoscopies and $0.3 \%$ to $3 \%$ in therapeutic colonoscopies $(4,5)$.

In a study conducted by lqbal et al. (6), the authors found that the number of perforations was higher in the rectosigmoid corner and the sigmoid colon (52\%). The results of the same study indicated that the perforation rates of the other segments of the colon were 17\% (cecum), 14\% (ascending colon), $7 \%$ (transverse colon), 8\% (descending colon), and 1\% (rectum). The authors also determined that the perforation areas were between 0.1 and $6.0 \mathrm{~cm}$ (mean: $1.7 \mathrm{~cm}$ ) in size. Electrocautery injuries result in small perforations, while mechanical injuries cause large perforations. In our series, most of the perforations (85.7\%) were seen in the sigmoid colon.

Colonoscopy-related perforations occur by three different mechanisms: mechanical trauma, pneumatic trauma, and post-therapeutic trauma. The factors that increase the risk of perforation during colonoscopy are old age, dramatic comorbidity, inflammatory intestinal disease, diverticulosis, steroid use, malignity, previous necrosis, invasive procedures, and insufficient experience of the endoscopist. Moreover, a previous history of abdominal surgery that causes a decrease in colonic and rectosigmoid movements, radiation, and adhesions result in acute intestinal angling; this increases the risk of perforation by increasing the difficulty of the colonoscopic procedure (7-9).

Findings and symptoms can be seen during the perforation, can be delayed, or can be asymptomatic according to the size and location of the perforation. Furthermore, breakthrough pain or failure to achieve sufficient distention in the lumen despite pushing air by colonoscopy may suggest perforation $(6,8)$. When patients are suspected to have perforations, standing direct abdominal radiography or lung radiography and left lateral decubitus abdominal radiography are initially performed. If the results of these radiographs are normal or a 
strong suspicion of perforation exists, abdominal computerized tomography (CT) with water-soluble contrast should be performed. CT aids in the diagnosis of free air, micro-punctures and/or abscesses (6). Cho et al. (10) showed that all patients had subdiaphragmatic free air following perforation. Six of our cases were diagnosed during colonoscopy, and their diagnoses were confirmed by standing direct abdominal radiography. Additional radiological imaging methods were unnecessary. Therefore, we believe that X-ray is an inexpensive and beneficial method to ascertain the existence of subdiaphragmatic free air.

There are three treatment modalities pertaining to postcolonoscopic perforations: conservative, endoscopic, and surgical. The fact that patients only have subdiaphragmatic free air is not an indication for surgical repair. Most patients with no peritoneal irritation or abdominal sepsis symptoms can be followed up with intravenous antibiotics treatment, suspension of oral intake, and serial abdominal examinations $(11,12)$. Conservative treatment results in shorter hospitalization and a low rate of morbidity in appropriate patients. Iqbal et al. (6) reported that of the 10 patients they treated and whose relatives refused surgical treatment, only one died. It has been suggested that small localized perforations with a subclinical progress can be completely closed without any problems. It was later observed in laparotomies performed for other reasons that the perforation areas closed in patients with subclinical perforations who had localized abdominal sensitivity and short-term fever (13). In our series, surgical procedures were performed as the primary treatment because the six patients who were diagnosed during colonoscopy had wide areas of perforation and the one patient who had delayed diagnosis manifested with acute abdomen.

Immediate surgical intervention is not necessary. Intraoperative findings determine the type of surgery to be performed in patients necessitating surgery. In cases where surgical intraabdominal contamination is limited, primary repair or post-resection primary anastomosis can be performed. Stoma can be considered in cases of intensive contamination. The number of laparoscopic colonic repairs for colorectal perforations has increased recently with developments in minimally invasive surgical procedures $(11,14)$. Zhang et al. (15) reported in their study that laparoscopic repair is a safe and feasible repair method. In our series, we performed primary repair in six out of seven laparotomy cases and performed the Hartmann procedure on the patient who had a delayed diagnosis. However, the patient who underwent primary repair of the ascending colon perforation was ascertained to have intestinal leakage in the postoperative period. This patient was re-operated and underwent a right hemicolectomy and end ileostomy.

Physicians have started to use endoscopic clips for the treatment of iatrogenic colonic perforations, which are increasing with the increasing number of endoscopic mucosal resections and submucosal dissection procedures. In a study conducted by Kim et al. (16), the authors ascertained 27 iatrogenic colonic perforation cases $(0.02 \%$ incidence) out of 115,285 colonoscopy procedures. Endoscopic clips were used to repair perforations in 16 of these patients, with success in 13 patients.

\section{CONCLUSION}

latrogenic colorectal perforations are rarely seen in endoscopy; however, they are among the most dangerous complications. Perforation management remains difficult and alarming for many endoscopists. The progress of colonoscopy-related perforations depends on the underlying diseases, mechanism of perforation, treatment modality performed, and experience of the treating physicians. Special attention should be paid to senior and comorbid patients receiving therapeutic procedures during colonoscopy.

Ethics Committee Approval: Authors declared that the research was conducted according to the principles of the World Medical Association Declaration of Helsinki "Ethical Principles for Medical Research Involving Human Subjects" (amended in October 2013).

Informed Consent: Informed consent was not received due to the retrospective nature of the study.

Peer-review: Externally peer-reviewed.

Author Contributions: Concept - E.G., H.Ç.; Design - E.G., U.A.; Supervision - D.A.Ç., A.S.S.; Resource - O.U.; Materials - E.G., K.C.D.; Data Collection and/or Processing - E.G.; Analysis and/or Interpretation - E.G., K.C.D.; Literature Search - K.C.D., U.A.; Writing Manuscript - E.G., U.A., D.A.Ç.; Critical Reviews - E.P., M.D.

Conflict of Interest: No conflict of interest was declared by the authors.

Financial Disclosure: The authors declared that this study has received no financial support.

\section{REFERENCES}

1. Juillerat $P$, Peytremann-Bridevaux I, Vader JP, Arditi C, Schusselé Filliettaz S, Dubois RW, et al. Appropriateness of colonoscopy in Europe (EPAGE II). Presentation of methodology, general results, and analysis of complications. Endoscopy 2009; 41: 240-246. [CrossRef]

2. Anderson ML, Pasha TM, Leighton JA. Enodoscopic perforation of the colon: lesson from a 10-year study. Am J Gastroenterol 2000: 95: 3418-3422. [CrossRef]

3. Araghizadeh FY, Timmcke AE, Opelka FG, Hicks TC, Beck DE. Colonoscopic perforations. Dis Colon Rectum 2001: 44: 713-716. [CrossRef]

4. Garbay JR, Suc B, Rotman N, Fourtanier G, Escat J. Multicentre study of surgical complications of colonoscopy. Br J Surg 1996: 83: 42-44. [CrossRef]

5. Gatto NM, Frucht H, Sundararajan V, Jacobson JS, Grann VR, Neugut Al. Risk of perforation after colonoscopy and sigmoidoscopy: a population-based study. J Natl Cancer Inst 2003: 95: 230-236. [CrossRef]

6. Iqbal CW, Chun YS, Farley DR. Colonoscopic perforations: a retrospective review. J Gastrointest Surg 2005; 9: 1229-1235. [CrossRef]

7. Lohsiriwat V. Colonoscopic perforation: Incidence, risk factors, management and outcome. World J Gastroenterol 2010; 16: 425-430. [CrossRef]

8. Bielawska B, Day AG, Lieberman DA, Hokey LC. Risk factors for early colonoscopic perforation include non-gastroenterologist endoscopists: a multivariable analysis. Clin Gastroenterol Hepatol 2014; 12: 85-92. [CrossRef]

9. Cobb WS, Heniford BT, Sigmon LB, Hasan R, Simms C, Kercher KW, et al. Colonoscopic perforations: incidence, management, and outcomes. Am Surg 2004; 70: 750-758.

10. Cho SB, Lee WS, Joo YE, Kim HR, Park SW, Park CH, et al. Therapeutic options for iatrogenic colon perforation: feasibility of endoscopic clip closure and predictors of the need for early surgery. Surg Endosc 2012; 26: 473-479. [CrossRef] 
Gündeş et al.

latrogenic colonic perforation

11. Mattei $P$, Alonso $M$, Justinich C. Laparoscopic repair of colon perforation after colonoscopy in children: report of 2 cases and review of the literature. J Pediatr Surg 2005; 40: 1651-1653. [CrossRef]

12. Erdem $H$, Çetinkünar $S$, Değer $K C$, Reyhan $E$, Tekeşin $K$, Görür $M$, et al. Management of iatrogenic colon perforations due to colonoscopy. Kolon Rektum Hast Derg 2014; 24: 133-139.

13. Macrae FA, Tan KG, Williams CB. Towards safer colonoscopy: a report on the complications of 5,000 diagnostic and therapeutic colonoscopies. Gut 1983; 24: 376-383. [CrossRef]
14. Hansen AJ, Tessier DJ, Anderson ML, Schlinkert RT. Laparoscopic repair of colonoscopic perforations: indications and guidelines. J Gastrointest Surg 2007; 11: 655 -659. [CrossRef]

15. Zhang YQ, Lu W, Yao LQ, Qin XY, Xu MD, et al. Laparoscopic direct suture of perforation after diagnostic colonoscopy. Int J Colorectal Dis 2013; 28: 1505- 1509. [CrossRef]

16. Kim JS, Kim BW, Kim JI, Kim JH, Kim SW, Ji JS, et al. Endoscopic clip closure versus surgery for the treatment of iatrogenic colon perforations developed during diagnostic colonoscopy: a review of 115,285 patients. Surg Endosc 2013; 27: 501-504. [CrossRef] 